\title{
Calculation of the Instream Ecological Flow of the Wei River Based on Hydrological Variation
}

\author{
Shengzhi Huang, Jianxia Chang, Qiang Huang, Yimin Wang, and Yutong Chen \\ State Key Laboratory Base of Eco-Hydraulic Engineering in Arid Area, Xian University of Technology, Xian 710048, China \\ Correspondence should be addressed to Jianxia Chang; chxiang@xaut.edu.cn
}

Received 10 October 2013; Revised 14 February 2014; Accepted 6 March 2014; Published 2 April 2014

Academic Editor: Y. P. Li

Copyright (C) 2014 Shengzhi Huang et al. This is an open access article distributed under the Creative Commons Attribution License, which permits unrestricted use, distribution, and reproduction in any medium, provided the original work is properly cited.

It is of great significance for the watershed management department to reasonably allocate water resources and ensure the sustainable development of river ecosystems. The greatly important issue is to accurately calculate instream ecological flow. In order to precisely compute instream ecological flow, flow variation is taken into account in this study. Moreover, the heuristic segmentation algorithm that is suitable to detect the mutation points of flow series is employed to identify the change points. Besides, based on the law of tolerance and ecological adaptation theory, the maximum instream ecological flow is calculated, which is the highest frequency of the monthly flow based on the GEV distribution and very suitable for healthy development of the river ecosystems. Furthermore, in order to guarantee the sustainable development of river ecosystems under some bad circumstances, minimum instream ecological flow is calculated by a modified Tennant method which is improved by replacing the average flow with the highest frequency of flow. Since the modified Tennant method is more suitable to reflect the law of flow, it has physical significance, and the calculation results are more reasonable.

\section{Introduction}

As known, river ecosystems play a significant role in watershed ecosystems, whose primary functions are purification, water storage, landscape, shipping, maintaining biodiversity, offering habitats for aquatic animals, and so on [1, 2]. Recently, the river ecosystems however are deteriorated under the background of climate change and increasingly intensified human activities (e.g., the construction of water conservancy project, conservation of water and soil, agricultural practices, etc.). As a result, the ecological chain is heavily destroyed, and a large number of species are decreasing on a large scale, some even die out. The core problem is that the flow in the river cannot satisfy the requirement of the ecological sustainable development due to unreasonable utilization of water resources and the neglect of the ecological flow. Therefore, the key step to improve river ecosystems is to reasonably calculate the instream ecological flow.

To date, about two hundred methods in the world have been introduced in the calculation of instream ecological flow [3-7]. Yang et al. [8] have used the improved Tennant method to calculate the instream ecological flow for the Irtysh
River. Chen et al. [9] have used the morphological methods which are based on the hydrological and morphological characteristics of river to compute ecological flow of the Liao Basin in China. Gippel and Stewardson [6] have used the wetted perimeter method to define the minimum environment flow. Dong et al. [10] have applied the monthly guarantee rate method to estimating the ecological water requirements for typical areas in the Huaihe Basin. Nevertheless, few of them have considered the hydrological variation when calculating the instream ecological flow. In fact, the runoff variations have occurred in many regions due to climate change and increasingly intensified human activities. The inflection point of the hydrological series causes the consistency of the entire hydrological series to be broken, and the overall distributions of the sample before and after the inflection point are different. Thus, it is not scientific and reasonable to compute instream ecological flow without considering hydrological variation which has changed the local ecological balance. It is thought that the local ecosystem has adapted to the hydrological status before hydrological variations. The river ecosystems before the change points of the hydrological series are better and healthier than those 
after them. Therefore, the instream ecological flow calculated based on the data before the hydrological variations is a more reasonable ecological water requirement. For this reason, it is necessary to take hydrological variations into account when the instream ecological flow is computed, which will help to reveal different influence factors on the instream ecological flow. Wei River, the biggest first grade tributary of the Yellow River in China, is located in the middle reach of the Yellow River. The Wei River Basin is an important region for China, especially for the establishment of the Guanzhong-Tianshui Economic Zone, which will rapidly promote the economic development in the entire western region. However, during the recent decades, the runoff in the Wei River Basin has a significantly decreasing trend caused by climate change and human activities, and the flow is seriously polluted, which results in severe ecological damages and will greatly restrict the economic and social development of the basin and will even affect the national economic development strategy. Therefore, it is of significant importance to calculate the instream ecological flow in the Wei River for the local watershed management department to reasonably allocate water resources, which will help to promote the recovery of the local river ecosystems.

Considering the seriousness of the river ecosystems damages in the Wei River Basin, many attempts have been made to estimate the instream ecological flow, thus improving the ecological conditions $[11,12]$. Pang et al. [11] have introduced a method considering not only the self-purification but also the flow demand for the aquatic animals' habitat to calculate the ecological base flow of the Wei River in Shaanxi province. Wang et al. [12] have used an approach based on water quality control target to estimate the lowest environmental water demands in the Wei River. However, to the best of our knowledge, none of them have considered the hydrological variations before computing the instream ecological flow, which is of significant importance to reasonably estimate the optimal instream ecological flow. Therefore, the hydrological variations are taken into consideration in this study.

Many traditional methods (e.g., Slide $F$ test, Slide $t$-test, Mann-Kendall test methods, etc.) were applied to detect inflection point in the field of hydrology. However, all those methods are based on the assumption that the hydrological data are stationary and linear. Conversely, they are nonstationary and nonlinear. Therefore, some deviations will occur if the conventional methods are employed to identify change points. Whereas the heuristic segmentation algorithm first proposed by Bernaola-Galván et al. [13] is used to tackle this problem successfully, which is based on the thought of sliding $t$-test and modified to detect the mean change point of nonlinear and nonstationary time series. Compared with the traditional methods, the heuristic segmentation algorithm can divide a nonstationary time series with some stationary subseries that have various physical backgrounds. Thus, this approach is employed in this research to detect the change point of runoff series.

Furthermore, motivated by Song et al. [14], who has pointed out that living beings adapt to the high frequency of environmental factors after long-term natural selection; the highest frequency of the runoff is regarded as the optimal instream ecological flow in this study. However, it is worth mentioning that the calculated optimal instream ecological values may be greatly higher than the monthly average flow after runoff variation due to the increasingly decreasing runoff at present. Therefore, the flow at present cannot meet the optimal instream ecological requirements. In view of reality and operability, the modified Tennant method is employed to compute the minimum instream ecological flow based on the calculated optimal instream ecological flow [3]. Thus, the main objectives of this study are (1) to detect the annual runoff change points in the Wei River Basin based on heuristic segmentation algorithm and (2) to reasonably estimate the maximum and minimum instream ecological monthly flow based on the highest frequency of monthly runoff and Tennant method.

\section{Study Area and Data}

2.1. Introduction of the Wei River Basin. The Wei River Basin, as shown in Figure 1, is selected in this study. The Wei River is the largest tributary of the Yellow River, which lies between $103.5^{\circ} \mathrm{E}-110.5^{\circ} \mathrm{E}$ and $33.5^{\circ} \mathrm{N}-37.5^{\circ} \mathrm{N}$, covering a total area of $1.35 \times 10^{5} \mathrm{~km}^{2}$. Located in the continental monsoon climate zone, the Wei River Basin is characterized by relative abundant precipitation and generally high temperatures in summer but by rare precipitation and very low temperatures in winter. The annual precipitation of the Wei River Basin is about $559 \mathrm{~mm}$ [15]. At the same time, the rainfall has a large seasonal variation that during flood season (from June to September) generally accounts for approximately $60 \%$ of the total annual rainfall. The annual rainfall also varies greatly due to the unstable features of the intensity, duration, and influencing area of the subtropical high pressure belt over the northern Pacific. For instance, the annual rainfall is more than $800 \mathrm{~mm}$ in wet years, whilst it is less than $370 \mathrm{~mm}$ in drought years, which is likely to result in highly frequent droughts and floods in the Wei River Basin. Topographically, the altitude decreases from the highest northwest mountainous area to the lowest Guanzhong Plain in the southeast and southern portion of the basin. The Guanzhong Plain is designated as a state key economic development zone, which will greatly promote the economic development of surrounding area. Therefore, the economic development of Guanzhong Plain will directly affect the sustainable development of economy and society in the basin. However, in recent decades, the runoff of the basin has a remarkable decreasing trend caused by the climate changes and human activities. According to Xiao et al., 2012 [16], with regards to Linjiacun station, the runoff during 1980-1990 and 19912000 was reduced by $52 \%$ and $42 \%$ compared with that during 1950-1959, respectively. Furthermore, the flow of the Wei River is seriously polluted on a large scale, leading to severe ecological damages, which will greatly restrict the economic and social development of this basin and will even affect national economic development strategy. For this reason, it is necessary for the local watershed management department to accurately calculate the instream ecological flow in the Wei 


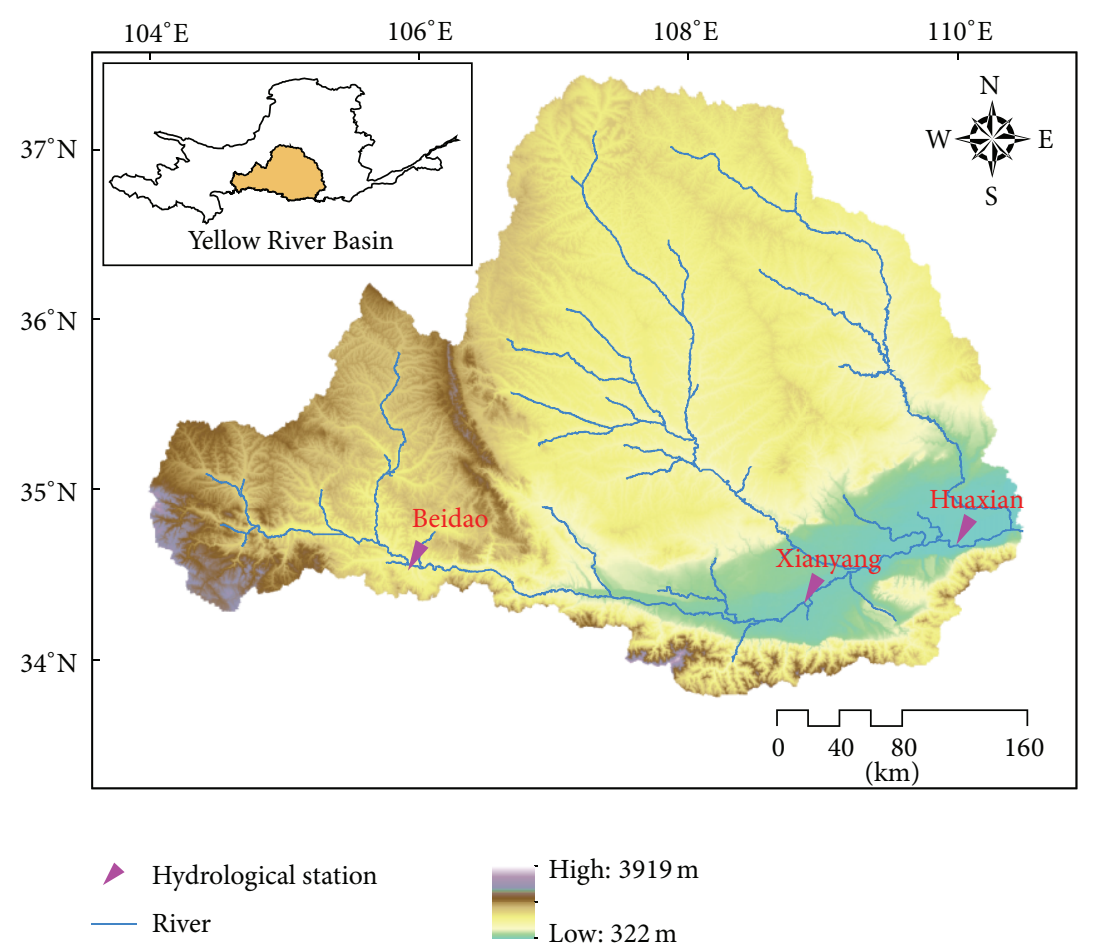

FIgURE 1: Location of Wei River and hydrological station in Yellow River Basin.

River, which will help to reasonably allocate water resources and promote the recovery of the local river ecosystems.

2.2. Study Data. Daily runoff data from Beidao, Xianyang, and Huaxian hydrological stations on the upper, middle, and lower reaches, respectively, of the Wei River is employed in this study. Amongst the three hydrological stations, the Beidao station has daily runoff data covering January 1, 1956December 31, 2010, the Xianyang station has daily runoff data covering January 1, 1960-December 31, 2006, and the Huaxian station has daily runoff data covering January 1, 1919December 31,2011. The monthly and annual data is calculated by the daily data from the hydrological stations. The data is acquired from the hydrologic manual and strictly controlled during their release. The Huaxian hydrological station has some missing data of several days, which is reconstructed by calculating the average value of its neighboring days at the same station. In our opinions, the missing data reconstructed approach has little effect on the study. In addition, the doublemass curve method is used to check the consistency of the data, and the results indicate that all the daily meteorological data used in the paper are consistent.

\section{Methodology}

3.1. Heuristic Segmentation Method. In order to divide a nonstationary time series into several stationary segments, a sliding pointer is moved step-by-step from left to right along the time series [13]. The average of the subset of the series to the left of the pointer $\mu_{1}$ and to the right $\mu_{2}$ is calculated.
For two Gaussian distributed random series, the difference between the averages of the two series $\mu_{1}$ and $\mu_{2}$ under the statistical significance is estimated by Student's $t$-test statistic as follows:

$$
t=\left|\frac{\mu_{1}-\mu_{2}}{S_{D}}\right|
$$

where

$$
S_{D}=\left(\frac{\left(N_{1}-1\right) s_{1}^{2}+\left(N_{2}-1\right) s_{2}^{2}}{N_{1}+N_{2}-2}\right)^{1 / 2}\left(\frac{1}{N_{1}}+\frac{1}{N_{2}}\right)^{1 / 2}
$$

denotes the pooled variance, $S_{1}$ and $S_{2}$ stand for the standard deviations of the two series, and $N_{1}$ and $N_{2}$ are the number of points from the two series. Moving the pointer along the given time series step-by-step, then statistic $t$ is calculated to estimate the difference between the averages of the right-side and left-side time series. Larger $t$ denotes that the average values of the two time series tend to be more significantly different. The largest $t$ value is regarded as a good candidate for the cut point. Then, the statistical significance $P\left(t_{\max }\right)$ is computed. It is worth mentioning that $P\left(t_{\max }\right)$ is not the standard Student's $t$-test since the series are not independent and cannot be obtained in a closed analytical form; therefore $P\left(t_{\max }\right)$ is approximately calculated as follows:

$$
P\left(t_{\max }\right) \approx\left\{1-I_{\left[v /\left(v+t_{\max }^{2}\right)\right]}(\delta v, \delta)\right\}^{\eta},
$$

where $\eta=4.19 \ln N-11.54$ and $\delta=0.40$ are acquired from Monte Carlo simulations, $N$ denotes the number of the time series to be cut, $v=N-2$, and $I_{x}(a, b)$ represents 
the incomplete beta function. If the difference in average is not statistically significant, for instance, if $P\left(t_{\max }\right)$ value is less than a threshold (normally set to 0.95), this time series is not divided. Conversely, the time series is divided into two segments whose averages are significantly different. If the time series is split, the iteration of the above procedure on each new segment continues until the acquired significance value is less than the threshold, or the length of the acquired segments is less than presupposed minimum segment length $\ell_{0}$.

3.2. Law of Tolerance. The growth and development of biology follows the laws of tolerance [17-19]. The law of tolerance is that there are biological minimum and maximum limits of various factors affecting the growth and development of biology. When the ecological factor is not between the upper and lower limitations, the biology will be degenerated and even die. Amongst many environmental factors, the factors which are close to or beyond the biological tolerance limitation and limit the development of biology are called the restriction factors. For a river ecosystem, flow, water flow rate, water level, water quality, and so on are its important ecological factors, and all of them are the function of flow. Therefore, flow is closely related to the limiting factors of river ecological system, which is also a greatly important limiting factor of river ecological system.

3.3. Ecological Adaptation Theory. The number of biology changes following the variation of a certain ecological factors, when the biological number reaches the maximum value, the corresponding ecological factor value is the optimal value for this species. Under the optimal environment, the number of this species is highest and the growth rate is fastest. Whereas the ecological factor deviates the optimal value and beyond the biological tolerance limitation, this species will stop growing and the number will reduce. Long-term natural selection makes creatures adapt to the higher frequency of environmental factors [14]. Therefore, the highest frequency of flow is regarded as the optimal instream ecological flow.

\subsection{Calculation of Instream Ecological Flow}

3.4.1. Kolmogorov-Smirnov (K-S) Test. The K-S test considers the null hypothesis that the cumulative distribution function (CDF) of a target distribution, represented by $F(x)$, is similar to the CDF of a reference distribution, $R(x)$. Thus, the K-S test is possible to judge whether the two distributions have the same CDFs [20].

When using a two-sample K-S test, the distance $D$ between two empirical distribution functions $F_{N 1}(x)$ and $R_{N 2}(x)$ is computed as

$$
D=\operatorname{Sup}_{-\infty<x<\infty}\left|F_{N 1}(x)-R_{N 2}(x)\right|,
$$

where $N_{1}$ and $N_{2}$ denote the number of data points in the first and second sample, respectively. Let

$$
N=\frac{N_{1} N_{2}}{N_{1}+N_{2}} .
$$

Then

$$
p(\sqrt{N} D>\lambda) \doteq \sum_{i=1}^{+\infty}(-1)^{i-1} e^{-2 i^{2} \lambda^{2}}
$$

The null hypothesis that the two distributions are similar is rejected at significance level $\alpha$, if $D^{*}=\sqrt{N} D$ is more than the corresponding critical value. The approximate $P$ value $p(D)$, that is termed the similarity probability in the vibration signal-processing literature, can be calculated by (6).

If the two distributions are similar $(D \rightarrow 0)$, then the similarity probability $p(D)$ approximates 1 . Otherwise, the similarity probability $p(D)$ approximates 0 .

3.4.2. Calculation of the Optimal Instream Ecological Flow. If there are change points of the hydrological series, the series before the change point is extremely different from that after the change point and the entire series is not inconsistent. It is thought that the local ecosystem has adapted to the hydrological status before hydrological variations, but the hydrological variations have changed the local ecological balance. Therefore, it is essential to use the hydrological series before hydrological variations to calculate the optimal instream ecological flow.

Based on the relationship between environmental factors and population, the highest frequency of flow is most suitable for river ecosystems. Since the flow of each month at the same station is different, the calculated highest frequency of flow for each month is regarded as the optimal instream ecological flow of the corresponding month; then the optimal instream ecological flow of different month in a year is calculated. In order to select the most suitable probability distribution function, Kolmogorov-Smirnov (K-S) method is employed to compute the test probability of monthly average flow [21]. Through calculating the test probability of each month at every station and comparing the fitting effect, the result indicates that GEV distribution is most suitable for the instream month average flow. follows:

The GEV probability density function is expressed as

$$
\begin{gathered}
f(x)=\frac{1}{\sigma}+(x)^{\xi+1} e^{-t(x)}, \\
t(x)= \begin{cases}\left(1+\xi \frac{x-\mu}{\sigma}\right)^{-1 / \xi} & \xi \neq 0 \\
e^{-(x-\mu) / w} & \xi=0,\end{cases}
\end{gathered}
$$

where $\sigma$ is scale parameter, which affects distribution scale; $\xi$ is shape parameter, which influences the distribution tail; $\mu$ is position parameter, which affects the distribution in a horizontal position. $L$-moment method is employed to estimate the parameter of GEV distribution [22]. The observed variable $X$ is in ascending order. $X_{j}$ represents the $j$ th value 
in the series; then the $L$-distance of the first three order $l_{1}, l_{2}$, $l_{3}$ and $L$-coefficient of skew $t_{3}$ is expressed as follows:

$$
\begin{aligned}
& l_{1}=n^{-1} \sum_{j=1}^{n} X_{j}, \\
& l_{2}=2 n^{-1} \sum_{j=2}^{n} \frac{(j-1)}{(n-1)} x_{j}-l_{1}, \\
& l_{3}=6 n^{-1} \sum_{j=3}^{n} \frac{(j-1)(j-2)}{(n-1)(n-2)} x_{j}-6 n^{-1} \sum_{j=2}^{n} \frac{(j-1)}{(n-1)} x_{j}+l_{1}, \\
& t_{3}=\frac{l_{3}}{l_{2}} .
\end{aligned}
$$

According to formula (9), the parameter of GEV distribution can be estimated as follows:

$$
\begin{aligned}
\xi & \approx-\left[7.859\left(\frac{2}{3+t_{3}}-\frac{\log 3}{\log 2}\right)+2.955\left(\frac{2}{3+t_{3}}-\frac{\log 3}{\log 2}\right)^{2}\right], \\
\sigma & =\frac{l_{2} \xi}{\left(1-2^{-\xi}\right) \Gamma(1+\xi)}, \\
\mu & =l_{1}+\frac{\sigma[\Gamma(1+\xi)-1]}{\xi},
\end{aligned}
$$

where $\Gamma(1+\xi)$ denotes gamma function.

Through the most valuable analysis of formula (7), the highest frequency of flow is calculated as follows:

$$
x=\frac{\sigma}{\xi}\left[(\xi+1)^{-\xi}-1\right]+\mu,
$$

where $x$ denotes the optimal instream ecological flow of every month.

3.4.3. Calculation of the Minimum Instream Ecological Flow. Since the monthly average flow before variation is higher than that after variation, it is very difficult to provide the optimal instream ecological flow due to the increasing water demand for the economic and social development. For this reason, the optimal instream ecological flow can be regarded as the maximum instream ecological flow. However, recently, the flow in the Wei River has a significantly decreasing trend, it is very difficult for the flow at present to satisfy the maximum instream ecological flow. Considering the reality and operability, the minimum instream ecological flow can be calculated by a modified Tennant method. In terms of the traditional Tennant method, the formula calculating the instream ecological flow is as follows:

$$
W_{t}=\sum_{i=1}^{12} M_{t} N_{i}
$$

where $W_{t}$ denote the instream ecological flow, $M_{i}$ are the average flow of the $i$ th month in a year, and $N_{i}$ represents

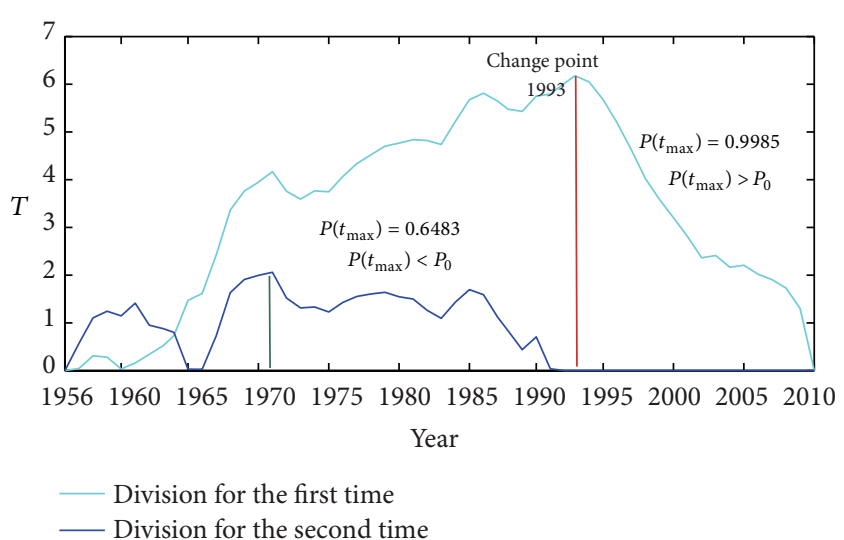

FIGURE 2: Segmentations and change points of annual runoff at Beidao station.

the recommended base flow percentage of the corresponding $i$ th month. Based on Tennant method, the monthly average flow is replaced by the calculated optimal instream ecological flow which can be better suitable to reflect the law of the monthly runoff. From October to March, the minimum instream ecological flow is computed by the corresponding optimal instream ecological flow multiplied by 0.2 ; from April to September, the minimum instream ecological flow is computed by the corresponding optimal instream ecological flow multiplied by 0.4 . The minimum instream ecological flow is used when the flow is insufficient, while the maximum instream ecological flow is employed when the runoff is abundant.

\section{Results}

\subsection{The Change Points of the Runoff at Each Hydrological Station}

4.1.1. The Change Points of the Runoff at Beidao Station. Since the annual runoff in the Wei River Basin has nonlinear and nonstationary characteristics, therefore, the heuristic segmentation method introduced in Section 3 is employed to detect the change points of the annual runoff. The threshold $P_{0}$ is set to 0.95 and $\ell_{0}$ is set to 25 . The segmentations and change points of annual runoff at Beidao station are exhibited in Figure 2. During the first iteration and segmentation process, a change point (1993) is identified due to its $P\left(t_{\max }\right)=$ $0.9985>P_{0}$. During the second iteration and segmentation, no change points are detected due to its $P\left(t_{\max }\right)=0.6483<$ $P_{0}$. When the second iteration finishes, the segmentation process ends due to the length of the segments that is less than $\ell_{0}$.

4.1.2. The Change Points of the Runoff at Xianyang Station. As in the same procedure as above, the threshold $P_{0}$ is set to 0.95 and $\ell_{0}$ is set to 25 . The segmentations and change points of annual runoff at Xianyang station are presented in Figure 3. During the first iteration and segmentation process, a change point $(1994)$ is detected due to its $P\left(t_{\max }\right)=0.9996>$ 


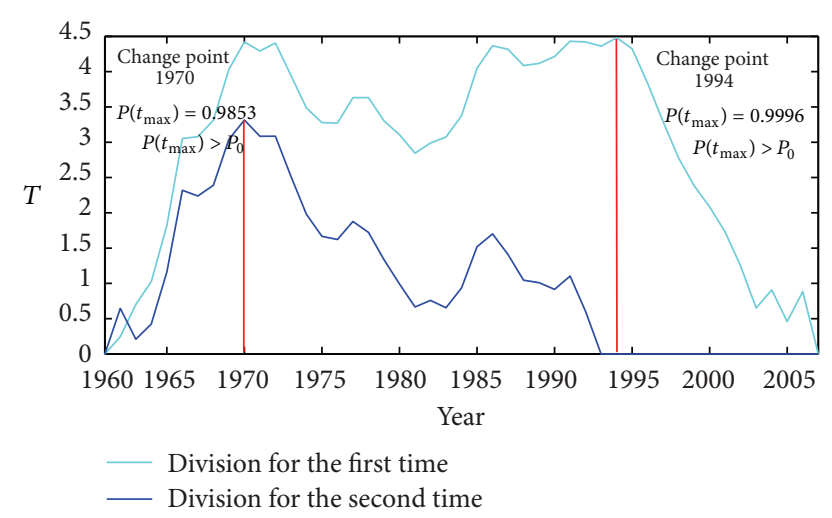

FIgURE 3: Segmentations and change points of annual runoff at Xianyang station.

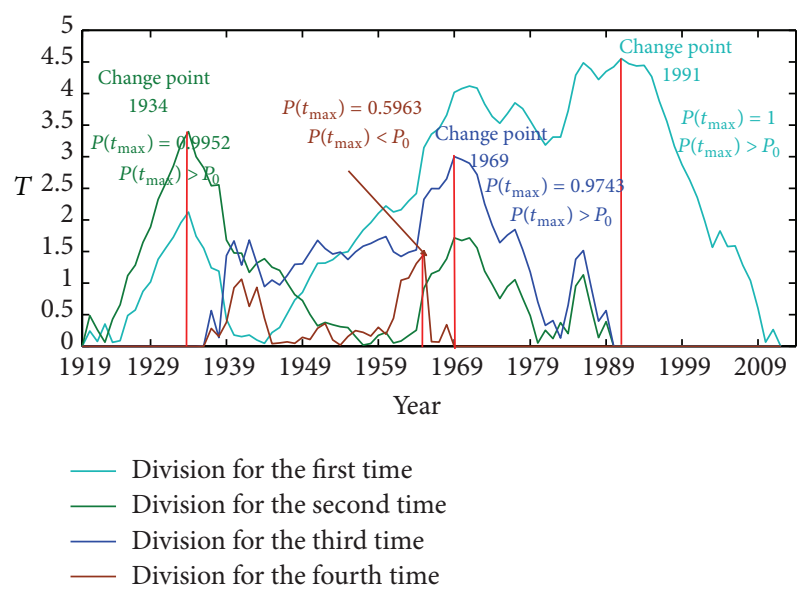

FIgURE 4: Segmentations and change points of annual runoff at Huaxian station.

$P_{0}$. During the second iteration and segmentation, another change point (1970) is found due to its $P\left(t_{\max }\right)=0.9853>P_{0}$. When the second iteration finishes, the segmentation process ends due to the length of the segments that is less than $\ell_{0}$.

\subsubsection{The Change Points of the Runoff at Huaxian Station.} Similarly, the threshold $P_{0}$ is set to 0.95 and $\ell_{0}$ is set to 25 . The segmentations and change points of annual runoff at Huaxian station is shown in Figure 4. During the first iteration and segmentation process, a change point (1991) is detected due to its $P\left(t_{\max }\right)=1>P_{0}$. During the second iteration and segmentation, another change point (1934) is found due to its $P\left(t_{\max }\right)=0.9952>P_{0}$. During the third iteration and segmentation process, another change point (1969) is identified due to its $P\left(t_{\max }\right)=0.9743>P_{0}$.

During the fourth iteration and segmentation process, no change points are found due to its $P\left(t_{\max }\right)=0.5963<P_{0}$. When the fourth iteration finishes, the segmentation process ends due to the length of the segments that is less than $\ell_{0}$.

Therefore, for the Beidao station, only one change point of annual runoff is identified. As regards to the Xianyang station, two change points was detected. With regards to the
Huaxian station, three change points are found. In view of the length of flow series and the degree of variation, the annual runoff covering 1919-1991 at Huaxian station is regarded as the series before variation, and the annual runoff during 1992-2011 is regarded as the series after variation; the annual runoff covering 1960-1994 at Xianyang station is regarded as the series before variation, and the annual runoff during 1995-2006 is regarded as the series after variation; the annual runoff covering 1956-1993 at Huaxian station is regarded as the series before variation, and the annual runoff during 1994-2010 is regarded as the series after variation.

\subsection{The Calculation Results of the Optimal Instream Ecological} Flow. As introduced in Section 3, the optimal (maximum) instream ecological flow is the highest frequency of monthly flow based on the GEV distribution before runoff variation. The $L$-moment method is used to estimate the parameter of GEV distribution, and the highest frequency of flow is computed according to formulas (11); then the corresponding instream ecological flow of every month at each station is calculated; the calculation results are presented in Table 1.

It can be easily observed from Table 1 that the maximum instream ecological flow from January to August at Beidao and Huaxian stations is increasing, whilst that from September to December is decreasing. Similarly, the maximum instream ecological flow at Xianyang station is increasing from January to September and decreasing from October to December. In general, the maximum instream ecological flow at Huaxian station is largest. Compared with the calculation results of Tennant method [3], most of the calculated maximum instream ecological flow of every month at each station are at the best level. The main reason is that the monthly runoff in this river is greatly decreasing and the monthly average flow after the variation is less than that before the variation. The frequency of monthly flow satisfying the maximum instream ecological flow in the Wei River is shown in Table 2. It can be obviously seen that the frequency of monthly flow satisfying the maximum instream ecological flow before the flow variation is extremely larger than that after the flow variation, especially for the Beidao station; the frequency of half of the months after variation is zero, implying that the river ecosystem is subject to severe damage after the flow variation. Comparatively, most of the frequencies of the three stations before the flow variation are larger than $40 \%$. The underlying cause of this phenomenon is increasingly intensifying human activities. The growing population and increasing economy result in a great reduction of runoff. With regards to Beidao station, the development of agriculture and animal husbandry need a lot of water, whilst regarding Xianyang and Huaxian stations, water demand in households and economic development have a very large proportion. Additionally, amongst the three hydrological stations, the frequency of monthly flow satisfying the maximum instream ecological flow at Xianyang station in nonflood season is lowest. The primary reason lies in the large number of water demand for economic and agricultural development. The Xianyang station is located in the Guanzhong Plain, and many industrial parks lie in the 
TABLE 1: The maximum instream ecological flow at three stations.

\begin{tabular}{lccc}
\hline \multirow{2}{*}{ Month } & \multicolumn{3}{c}{ Hydrological stations } \\
& Beidao $\left(10^{8} \mathrm{~m}^{3}\right)$ & Xianyang $\left(10^{8} \mathrm{~m}^{3}\right)$ & Huaxian $\left(10^{8} \mathrm{~m}^{3}\right)$ \\
\hline January & 0.3693 & 1.4157 & 2.214 \\
February & 0.4164 & 1.2969 & 2.2344 \\
March & 0.6508 & 1.4179 & 2.9864 \\
April & 0.7763 & 1.6253 & 3.1216 \\
May & 1.1252 & 2.1386 & 4.2134 \\
June & 1.124 & 2.6713 & 4.8661 \\
July & 2.2039 & 3.2768 & 11.616 \\
August & 2.3685 & 4.9855 & 13.4456 \\
September & 2.2127 & 10.0234 & 11.3155 \\
October & 1.8079 & 8.6294 & 8.5133 \\
November & 0.8667 & 4.1154 & 4.3768 \\
December & 0.469 & 2.0948 & 2.7472 \\
\hline
\end{tabular}

area above the station. Thus, during the nonflood period, a lot of water is used for industrial manufacture, thereby leading to less flow failing to satisfy the ecological demand.

In theory, the maximum instream ecological flow is most suitable for the healthy development of the river ecosystem in this basin, when the flow is sufficient; the maximum instream ecological flow can be used as the instream ecological water requirements to provide during high flow year. However, since the monthly flow has a significant decreasing trend caused by climate change and the increasingly intensified human activities, in practice, it is difficult for the flow at present to satisfy the optimal (maximum) instream ecological flow. Therefore, it is necessary to calculate the minimum instream ecological flow when the flow is insufficient, which can be used to ensure the sustainable development of the river ecosystems under the bad circumstance.

4.3. The Calculation Results of the Minimum Instream Ecological Flow. According to Section 3, the minimum instream ecological flow is calculated by a modified Tennant method, which is based on the Tennant method and replaced by the monthly average flow with the calculated maximum instream ecological flow. The calculation results of the Tennant method and the modified Tennant approach are exhibited in Table 3.

For Beidao station, the minimum instream ecological flow calculated by the modified Tennant method is always larger than that computed by Tennant method, but the difference between them is small. For Xianyang station, all the minimum instream ecological flows calculated by the modified Tennant method are larger than that calculated by Tennant method except the minimum instream ecological flow of April and May. For Huaxian station, the minimum instream ecological flow of April, May, September, and October computed by the modified Tennant method is less than that calculated by Tennant method. In general, the minimum instream ecological flow calculated by the modified Tennant method is slightly larger than that computed by Tennant method. Since the modified Tennant method is based on the highest frequency of monthly flow and has physical significance, therefore the minimum instream ecological flow calculated by the modified Tennant method is more reasonable than that calculated by Tennant method.

\section{Discussion}

It is worth mentioning that $P_{0}$ and $\ell_{0}$ are two important parameters for the heuristic segmentation method to identify the change points. The magnitudes of $P_{0}$ and $\ell_{0}$ will directly affect the identification of the mutation points and further influence the calculated maximum and minimum instream ecological flow. The threshold $P_{0}$ is set to 0.95 and $\ell_{0}$ is set to 25 , which is determined by empirical analysis and subjective to some extent.

The results show that the decreasing runoff in the Wei River Basin is affected by human activities and climate change, and the human activities are the most primary driving factor. There are two primary change points of annual runoff in the Wei River, which are the early the 1970s and the middle 1990s, respectively.

Firstly, the causes of the first change point are analyzed. As known, the soil conservation measures in the Wei River Basin were carried out in the 1950s and expanded on a large scale after the early 1970s, which will obviously reduce the runoff. Besides, the Wei River Basin is in the continental monsoon climate zone of China and influenced by the West Pacific Subtropical high pressure system. In 1972, the weakness of this system in combination with development of an El Niño event caused substantial atmospheric circulation and climate anomalies in China [23], resulting in a sharp reduction in rainfall in the basin, which contributes to the mutation point identified in that year. Furthermore, there are many reservoirs and irrigation canals completed in the early 1970s (e.g., the Yangmaowan reservoir and Fengcun reservoir are completed in 1970, the Dayu reservoir and Shimen reservoir are constructed in 1972 and the Baojixia canal completed in 1971), which will highly reduce the runoff and induce the change point.

Lastly, the causes of the second inflection point are analyzed. National economic water consumption sectors in the Wei River Basin in the 1990s have remarkably increased, especially in domestic and industrial water use. The total national economy water consumption is 4.3 billion $\mathrm{m}^{3}$, which is increased by $52.6 \%$ compared to the time period before 1990 s, directly resulting in the decreasing runoff. Moreover, according to Zhang [15], a third ENSO event occurred in 1994, when the West Pacific Subtropical high pressure system was strong, which resulted in an extreme drop in rainfall in the basin, contributing to a $42.4 \%$ reduction in average annual runoff.

As there are change points of the runoff series in the Wei River and the variation has broken the ecological balance before the flow variation, it is necessary to take the variation into account when calculating the instream ecological flow. It is worth noting that the instream ecological flow considered about the variation tends to be larger than that without considering the variation due to the decreasing flow. 
TABLE 2: The frequency of monthly flow satisfying the maximum instream ecological flow in the Wei River.

\begin{tabular}{|c|c|c|c|c|c|c|}
\hline \multirow{2}{*}{ Month } & \multicolumn{2}{|c|}{ Beidao station } & \multicolumn{2}{|c|}{ Xianyang station } & \multicolumn{2}{|c|}{ Huaxian station } \\
\hline & $\mathrm{BFV}(\%)$ & $\operatorname{AFV}(\%)$ & BFV (\%) & $\operatorname{AFV}(\%)$ & BFV (\%) & $\operatorname{AFV}(\%)$ \\
\hline January & 46 & 0 & 28 & 0 & 40 & 5 \\
\hline February & 52 & 0 & 33 & 7 & 44 & 9 \\
\hline March & 51 & 0 & 58 & 14 & 41 & 14 \\
\hline April & 35 & 0 & 64 & 14 & 55 & 27 \\
\hline May & 46 & 0 & 73 & 28 & 51 & 27 \\
\hline June & 35 & 7 & 48 & 7 & 41 & 14 \\
\hline July & 41 & 7 & 70 & 28 & 40 & 14 \\
\hline August & 35 & 4 & 42 & 14 & 35 & 9 \\
\hline September & 38 & 4 & 36 & 7 & 48 & 18 \\
\hline October & 46 & 11 & 27 & 14 & 45 & 32 \\
\hline November & 33 & 4 & 24 & 7 & 56 & 27 \\
\hline December & 38 & 0 & 27 & 0 & 40 & 14 \\
\hline
\end{tabular}

Note: BFV denotes before flow variation and AFV denotes after flow variation.

TABLE 3: The minimum instream ecological flow of the Wei River.

\begin{tabular}{|c|c|c|c|c|c|c|}
\hline \multirow{2}{*}{ Month } & \multicolumn{2}{|c|}{ Beidao station } & \multicolumn{2}{|c|}{ Xianyang station } & \multicolumn{2}{|c|}{ Huaxian station } \\
\hline & MTM & TM & MTM & TM & MTM & TM \\
\hline January & 0.0739 & 0.06227 & 0.2831 & 0.2074 & 0.4428 & 0.3807 \\
\hline February & 0.0833 & 0.069 & 0.2594 & 0.19586 & 0.4469 & 0.3851 \\
\hline March & 0.1302 & 0.1013 & 0.2836 & 0.2691 & 0.5973 & 0.5248 \\
\hline April & 0.3105 & 0.2200 & 0.6501 & 0.9618 & 1.2487 & 1.5203 \\
\hline May & 0.4501 & 0.3272 & 0.8554 & 1.3871 & 1.6854 & 2.0202 \\
\hline June & 0.4496 & 0.3783 & 1.0685 & 0.9779 & 1.9464 & 1.7816 \\
\hline July & 0.8816 & 0.6755 & 1.3107 & 2.0110 & 4.6464 & 4.0136 \\
\hline August & 0.9474 & 0.7178 & 1.9942 & 1.7417 & 5.3782 & 4.5461 \\
\hline September & 0.8851 & 0.6641 & 4.0094 & 2.9904 & 4.5262 & 5.1085 \\
\hline October & 0.3616 & 0.2930 & 1.7259 & 1.2367 & 1.7027 & 1.9978 \\
\hline November & 0.1733 & 0.1296 & 0.8231 & 0.5693 & 0.8754 & 0.9926 \\
\hline December & 0.0938 & 0.0694 & 0.4190 & 0.2713 & 0.5494 & 0.4949 \\
\hline
\end{tabular}

Note: MTM denotes the modified Tennant method and TM denotes Tennant method.

\section{Conclusion}

Recently, the Wei River Basin has witnessed a severe destruction of river ecosystems. The key way to solve this problem is to reasonably allocate water resources and ensure the basic requirement water of river ecosystem. The core problem is to accurately calculate instream ecological flow. Under the background of climate change and increasing identified human activities, there are some change points of the runoff series in the Wei River. In order to reasonably compute the instream ecological flow, the variation is taken into consideration in this study. The heuristic segmentation algorithm is employed to identify the change points due to the nonlinear and nonstationary flow series, which is difficult for the traditional statistical test to accurately detect the change points. The diagnosis results suggest that the runoff of Beidao station has a change point (1991); the runoff of Xianyang station has two change points (1970 and 1994); the runoff of Huaxian station has three change points (1934, 1969 and 1991).

Based on the law of tolerance and ecological adaptation theory, the optimal (maximum) instream ecological flow is calculated in this study, which is the highest frequency of the monthly flow from the GEV distribution. Since the monthly flow before the variation is larger than that after the variation, the optimal instream ecological flow is difficult to provide due to the decreasing runoff. In order to guarantee the sustainable development of river ecosystems under some bad circumstances, the minimum instream ecological flow is calculated by a modified Tennant method which is improved by replacing the average flow with the highest frequency of flow based on the GEV distribution. Since the modified Tennant method is more suitable to reflect the law of flow, it has physical significance, and the calculation results are more reasonable. The maximum and minimum instream 
ecological flow is a greatly important reference for protection and restoration of the river ecosystems in the Wei River Basin.

\section{Conflict of Interests}

The authors declare that there is no conflict of interests regarding the publication of this paper.

\section{Acknowledgments}

This research was supported by the National Major Fundamental Research Program (2011CB403306), the National Natural Fund Major Research Plan (51190093), and the Natural Science Foundation of China (51179148, 51179149). Sincere gratitude is extended to the editor and anonymous reviewers for their professional comments and corrections, which greatly improved the presentation of the paper.

\section{References}

[1] Z.-R. Dong, "Diversity of river morphology and diversity of biocommunities," Journal of Hydraulic Engineering, vol. 48, no. 11, pp. 1-6, 2003 (Chinese).

[2] J. Gao, Y. Gao, G. Zhao, and G. Hörmann, "Minimum ecological water depth of a typical stream in Taihu Lake Basin, China," Quaternary International, vol. 226, no. 1-2, pp. 136-142, 2010.

[3] D. L. Tennant, "Instream flow regimens for fish, wildlife, recreation, and related environmental resources," in Proceedings of Symposium and Special Conference on Instream Flow Needs II, J. F. Osborn and C. H. Allman, Eds., pp. 359-373, American Fisheries Society, Bethesda, Md, USA, 1976.

[4] X. Xia, Z. Yang, and Y. Wu, "Incorporating eco-environmental water requirements in integrated evaluation of water quality and quantity-a study for the Yellow River," Water Resources Management, vol. 23, no. 6, pp. 1067-1079, 2009.

[5] N. D. Gordon, T. A. McMahon, and B. L. Finlayson, Stream Hydrology: An Introduction for Ecologists, John Wiley \& Sons, New York, NY, USA, 2nd edition, 2004.

[6] C. J. Gippel and M. J. Stewardson, "Use of wetted perimeter in defining minimum environmental flows," River Research and Applications, vol. 14, no. 1, pp. 53-67, 1998.

[7] S. Liu, X. Mo, J. Xia et al., "Uncertainty analysis in estimating the minimum ecological instream flow requirements via wetted perimeter method: curvature technique or slope technique," Acta Geographica Sinica, vol. 61, no. 3, pp. 273-281, 2006.

[8] F. Yang, Z. Xia, L. Yu, and L. Guo, "Calculation and analysis of the instream ecological flow for the Irtysh River," Procedia Engineering, vol. 28, pp. 438-441, 2012.

[9] M. Chen, G. Wang, H. Feng, and L. Wang, "The calculation of river ecological flow for the Liao basin in China," Procedia Engineering, vol. 28, pp. 715-722, 2012.

[10] X. Dong, P. Du, Q. Tong, and J. Chen, "Ecological water requirement estimates for typical areas in the huaihe basin," Tsinghua Science and Technology, vol. 13, no. 2, pp. 243-248, 2008.

[11] B. Pang, Z. X. Xu, and W. Wu, "Estimation of the ecological base flow of Wei River in Shaanxi province," Procedia Environmental Sciences, vol. 13, pp. 1559-1568, 2012.

[12] X. Q. Wang, Z. F. Yang, and C. M. Liu, "Method of resolving the lowest environmental water demands in river course (II) - application," Acta Scientiae Cirgumstantiae, vol. 21, no. 5, pp. 549$552,2001$.
[13] P. Bernaola-Galván, F. C. Ivanov, L. A. Nunes Amaral, and H. E. Stanley, "Scale invariance in the nonstationarity of human heart rate," Physical Review Letters, vol. 87, no. 16, Article ID 168105, 4 pages, 2001.

[14] L.-L. Song, G.-H. Lu, and L. Liu, "Estimation of instream flow based on hydrological indexes," Journal of Hydraulic Engineering, vol. 37, no. 11, pp. 1336-1341, 2006.

[15] H. L. Zhang, Y. Chen, and G. X. Ren, "The characteristics of precipitation variation of Weihe River Basin in Shaanxi Province during recent 50 years," Agricultural Research in the Arid Areas, vol. 26, pp. 236-240, 2008.

[16] J. Xiao, J. G. Luo, J. Xie, and C. Chen, "Analysis on interannual and annual variation trend of runoff in the main stream of Weihe River," Yellow River, vol. 34, no. 11, pp. 32-36, 2012 (Chinese).

[17] Ü. Niinemets and F. Valladares, "Environmental tolerance," in Encyclopedia of Ecology, S. E. Jørgensen and B. D. Fath, Eds., pp. 1370-1376, Elsevier, Oxford, UK, 2008.

[18] V. E. Shelford, "Some concepts of bioecology," Ecological Society of America, vol. 12, no. 3, pp. 455-467, 1931.

[19] A. Mackenzie, A. S. Ball, and S. R. Virdee, Instant Notes in Ecology, Instant Notes Series, BIOS Scientific Publishers, London, UK, 2nd edition, 2001.

[20] X. Wang and V. Makis, "Autoregressive model-based gear shaft fault diagnosis using the Kolmogorov-Smirnov test," Journal of Sound and Vibration, vol. 327, no. 3-5, pp. 413-423, 2009.

[21] F. J. Messey, "The Kolmogorov-Smirnov test for goodness of fit," Journal of the American Statistical Association, vol. 46, no. 253, 1951.

[22] J. R. M. Hosking, " $L$-moments: analysis and estimation of distributions using linear combinations of order statistics," Journal of the Royal Statistical Society. Series B. Methodological, vol. 52, no. 1, pp. 105-124, 1990.

[23] Z. X. Bao, J. Y. Zhang, and G. Q. Wang, "Attribution for decreasing streamflow of the Haihe River basin, northern China: climate variability or human activities," Journal of Hydrology, vol. 407, pp. 117-129, 2012. 


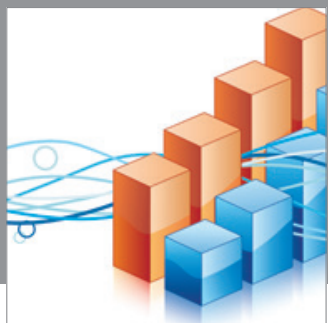

Advances in

Operations Research

mansans

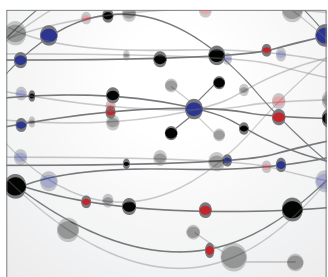

The Scientific World Journal
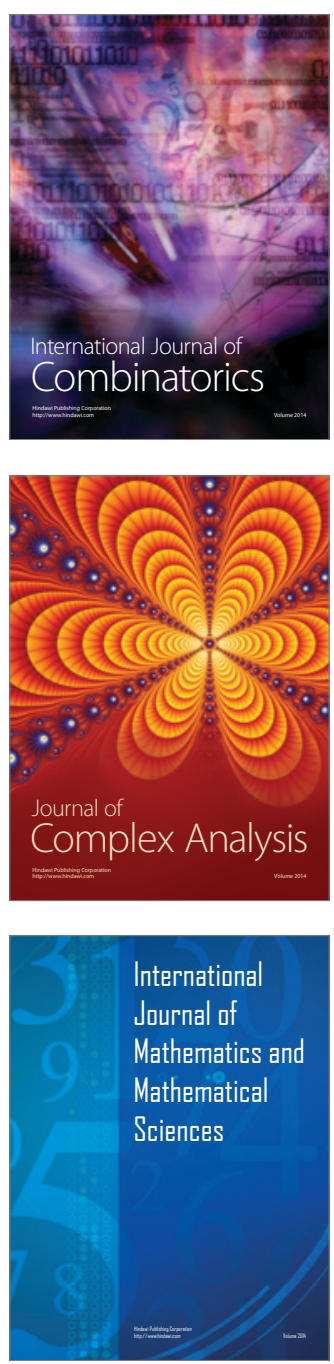
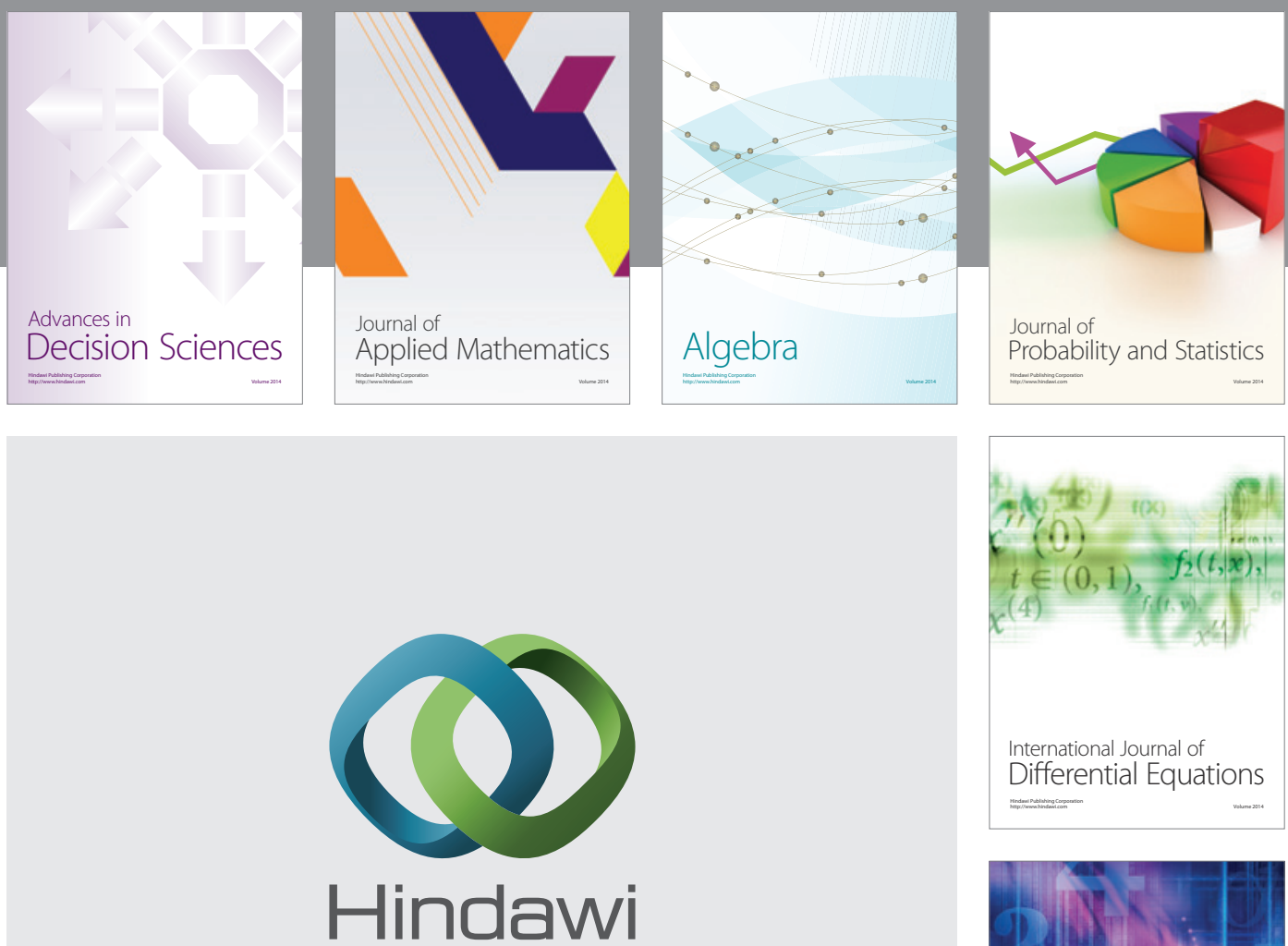

Submit your manuscripts at http://www.hindawi.com
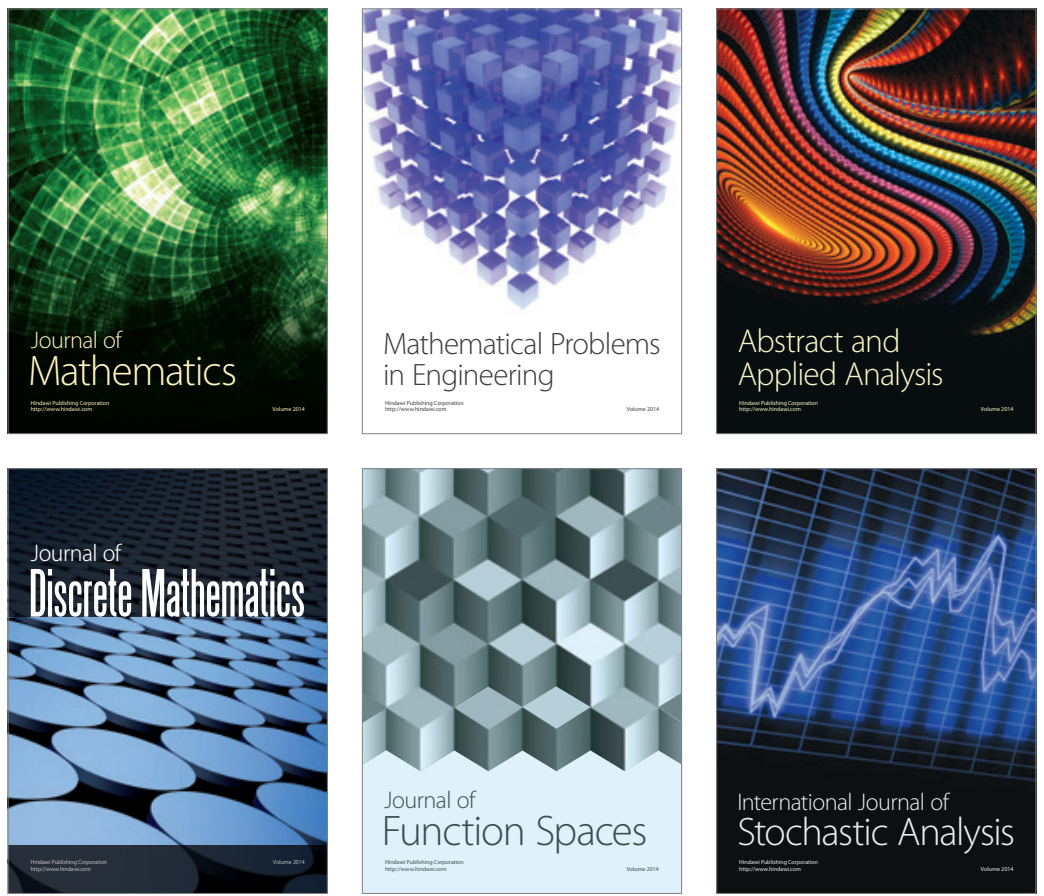

Journal of

Function Spaces

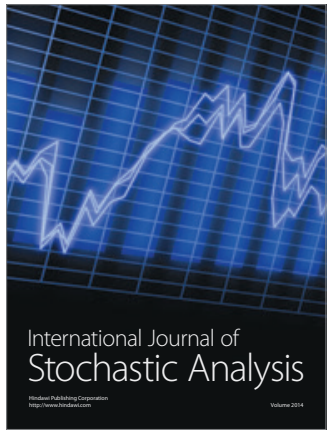

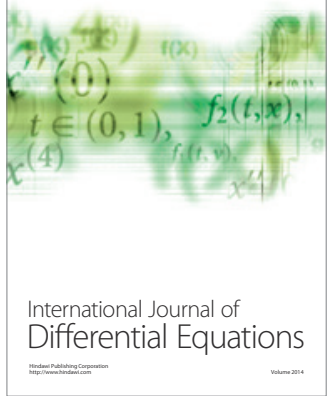
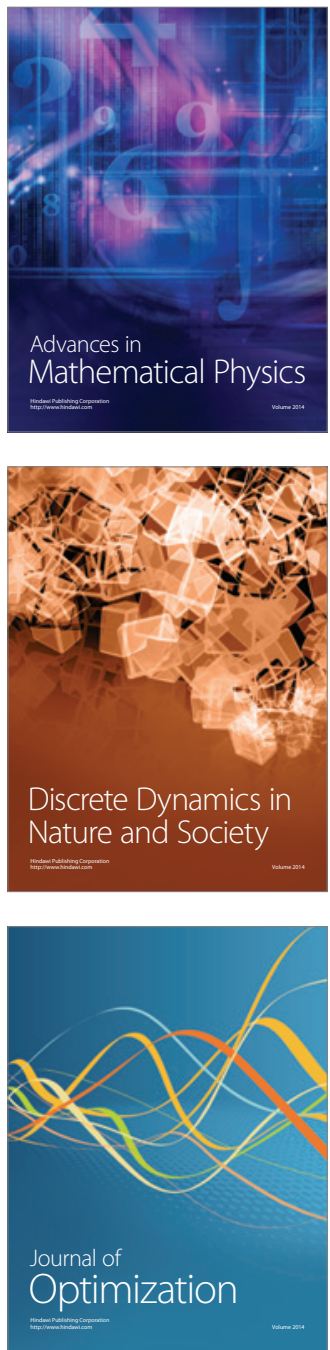